\title{
Research Square \\ Effect of Different Moisture Content on Mechanical Parameters of Red Clay Under Freeze-Thaw Cycle
}

\section{Bin Lin}

Anhui University of Science and Technology

\section{Zhuhua Tian ( $18130560951 @ 163 . c 0 m$ )}

Anhui University of Science and Technology

Liang Jiang

Anhui University of Science and Technology

Yongjia Zhao

Anhui University of Science and Technology

\section{Research Article}

Keywords: freeze-thaw cycle, soil strength, stress-strain curve, cohesion

Posted Date: October 26th, 2021

DOl: https://doi.org/10.21203/rs.3.rs-988887/v1

License: (c) (i) This work is licensed under a Creative Commons Attribution 4.0 International License. Read Full License 


\title{
Effect of Different Moisture Content
}

\section{on Mechanical Parameters of Red}

\section{Clay under Freeze - thaw Cycle}

Bin Lin ${ }^{凶}$, Zhuhua Tian, Liang Jiang \& Yongjia Zhao

School of Civil Engineering and Architecture, Anhui University of Science and Technology, Huainan, 232001, China.

\begin{abstract}
One of the causes of damage in cold area projects is the freeze-thaw cycling action, which causes large changes in soil strength, resulting in soil deformation and destroying its soil stability. In order to investigate the effect of water content on the mechanical parameters of red clay soil under the action of freeze-thaw cycles, the solidification undrained triaxial test and consolidation test were carried out with red clay soil in Changzhi area, Shanxi Province, as the research object. The test results show that the stress-strain curve is hardening curve, with the increase of water content, the maximum shear stress, cohesion, internal friction angle, elastic modulus, compression modulus and shear modulus are decreasing, and Poisson ratio is gradually increasing. The mechanical parameters of o freeze-thaw cycles are greater than 12 freeze-thaw cycles. With the increase in water content, the difference in shear stress between two freeze-thaw cycles was decreasing under the same circumferential pressure. o freeze-thaw cycles, the decreasing trend of cohesion increased from $4.48 \%$ to $35.88 \%$, and the elastic modulus decreased up to $69.61 \% .12$ freeze-thaw cycles, the decreasing trend of cohesion decreased from $65.38 \%$ to $5.93 \%$, and the elastic modulus showed a linear decreasing relationship. The decreasing trend of the internal friction angle remained consistent with the gradual increase. The Poisson ratio was $0.21-0.29$ and $0.24-0.31$ for the two cycles, respectively. The shear modulus at o freeze-thaw cycles was 1.86-1.16 times higher than that at 12 freeze-thaw cycles, and the difference decreased gradually with the increase in water content. The increase in water content made the soil more prone to shear deformation.
\end{abstract}

\section{Introduction}

One reason for damage in cold area projects is the freeze-thaw cycle effect, which causes large changes in soil strength and deformation of the soil, and the reason for inducing this change is that the freeze-thaw cycle changes the internal structure of the soil and destroys its soil stability ${ }^{1-3}$. Red clay in China is mainly distributed in Guangxi, Yunnan and Guizhou areas, but they also distributed it in some areas of Shanxi. The main components of red clay are kaolinite and illite, red clay with swelling characteristics contains a small amount of montmorillonite, which belongs to the medium characteristics of swelling soil ${ }^{4-9}$, and red clay in Changzhi area of Shanxi has certain swelling characteristics, cold season, the temperature will be to minus a dozen degrees Celsius, red clay will freeze and swell, and the freezing of red clay will melt when the temperature rises, and this repeatedly, will inevitably The red clay structure will be damaged and the mine and slope works in the area will be threatened.

Moisture content is an important influencing factor in the variation of soil properties. Changes in water 
content change the state of connection and contact between particles within the soil, thus significantly affecting the macroscopic properties of the soil ${ }^{10-12}$. Ahmed et al. investigated the physical and mechanical properties of silt soils with different water contents, and from them, found the optimum water content for optimal physical and mechanical properties ${ }^{13}$. In combination with triaxial tests, $\mathrm{Xu}$ et al. investigated the effect of water content on the strength of frozen loess and showed that the water content had a significant effect on the stress-strain curve and dominated the evolution of mechanical properties ${ }^{14}$.

As is known to all, the freeze-thaw cycles have an important effect on the mechanical parameters of soils. Therefore, many scholars have conducted more studies on soils under freeze-thaw cycles. The results from previous studies show that the shear strength and elastic modulus of soils decrease with the increase in the number of freeze-thaw cycles and Poisson's ratio increases with the increase in the number of freeze-thaw cycles ${ }^{15-16}$. In addition, Shastri et al. investigated the effect of freeze-thaw cycles on the shear strength of soils by establishing an elasticity model, and they found that this method could capture the key characteristics of the mechanical behavior of frozen soils ${ }^{17}$. Liu et al. studied the shear strength and the strength change mechanism by triaxial, studied the shear strength and the mechanism of strength change by triaxial tests and microscopic observation ${ }^{18}$. Many scholars studied the mechanical behavior of clay under the effect of freeze-thaw cycles by triaxial compression tests, and they found that the effect on the mechanical properties became more and more significant with the increase in the number of freeze-thaw cycles $^{19}$.Wang et al. studied the effect of freeze-thaw cycles on the shear strength of clay by using triaxial tests and proposed the concept of correction coefficient of strength index, and the study showed that the soil The strength and angle of internal friction and cohesion gradually decrease and stabilize with the increase of freeze-thaw cycles ${ }^{20}$.Tian et al. investigated the triaxial test of freeze-thaw cycles on powdered clay with dynamic properties and found that freeze-thaw cycles increase the elastic strain of the soil, and the soil gradually develops from plastic damage to brittle damage as the surrounding pressure increases ${ }^{21}$. Cheng et al. found that saline soils exhibit strain hardening characteristics with or without freeze-thaw cycles by triaxial consolidation tests, and used logistics functions to predict the degradation law of shear strength index ${ }^{22}$.The Poisson ratio is a very important mechanical parameter of soils and can be got in various ways. Among the soil mechanics studies and tests, instrumental measurements and theoretical derivations can calculate it $\mathrm{it}^{23-25}$.

In recent years, more and more scholars have in-depth studies on freeze-thaw cycle consolidation tests. Wang et al. concluded that the thawing settlement of powdered clay increased after freeze-thaw cycles based on the measured settlement characteristics, and the settlement rate first increased and then decreased and eventually stabilized ${ }^{26}$.

Ozgan et al. used consolidation tests to determine the effect of freeze-thaw on consolidated soils and determined that the consolidated settlement increased by $23 \%$ after a certain number of freeze-thaw cycles ${ }^{27}$. Another part of scholars, used the changes in the internal microscopic pore structure of soils before and after consolidation by freeze-thaw cycles to elucidate the mechanism of freeze-thaw consolidation of soils ${ }^{28-29}$.

From previous studies, the mechanical properties of red clay soils after freeze-thaw cycles have been less studied. In this paper, we take remodeled red clay soils as the research object and systematically analyze the laws of water content on the strength, cohesion, internal friction angle, elastic modulus and compression modulus of red clay soils after freeze-thaw cycles through triaxial tests and consolidation test studies after 0 freeze-thaw cycles and 12 freeze-thaw cycles of stabilization. The Poisson's ratio and shear modulus of the red clay are calculated with the help of the Poisson's ratio derivation theory at the complete lateral limit. This paper can provide some reference value for cold area projects where red clay soils exist. 


\section{Materials and methods}

Samples preparation. It took the red clay used in this study from Changzhi area of Shanxi Province, China. The soil samples were drilled at the site and transported back to the laboratory. After air drying, the soil samples were crushed and passed through a $2 \mathrm{~mm}$ fine sieve, and sufficient soil samples for test were taken and put into an oven for drying. Because the moisture content of undisturbed soil in this area is between $17.0 \%$ and $23.7 \%$, the soil samples of $15 \%, 18 \%, 21 \%$ and $24 \%$ are prepared according to the range of $3 \%$ moisture content difference. I put the allocated soil samples into the maintenance box for 24 hours. After the maintenance, the triaxial test soil samples with the size of $39.1 \mathrm{~mm} \times 80 \mathrm{~mm}$ and $20 \mathrm{~mm} \times$ $61.8 \mathrm{~mm}$ were made, respectively. Each moisture content of 18 soil samples in the triaxial test was 72 , and each moisture content of 24 soil samples in the consolidation compression test was 96.

Experimental design. This experiment studies the effect of different water contents on the mechanical parameters of remolded red clay under the action of freeze-thaw cycle. It described the test process as follows. First, the prepared remolded red clay samples were divided into two groups. One group was not subjected to freeze-thaw cycle test, and it subjected the other group to freezing at $-10{ }^{\circ} \mathrm{C}$ for $12 \mathrm{~h}$, and then thawing at $20^{\circ} \mathrm{C}$ for $12 \mathrm{~h}$. After each freeze-thaw process, the height of the sample was measured and repeated until the measured height did not change and the freeze-thaw was stable. Second, consolidated undrained triaxial shear tests with a shear rate of $0.008 \% / \mathrm{mm} / \mathrm{min}$ and confining pressures of $100 \mathrm{kPa}, 200$ $\mathrm{kPa}$ and $300 \mathrm{kPa}$, respectively. Merged compression tests were conducted on soil samples with vertical pressures of $50 \mathrm{kPa}, 100 \mathrm{kPa}, 200 \mathrm{kPa}$ and $400 \mathrm{kPa}$, respectively. It showed basic physical parameters of red clay in table 1.

\begin{tabular}{|c|c|c|c|c|}
\hline Dry density $\boldsymbol{\rho}_{\mathrm{d}} /\left(\mathrm{g.cm}^{-\mathbf{3}}\right)$ & Proportion $\boldsymbol{G}_{\mathbf{S}}$ & Liquid limit $\boldsymbol{I}_{\mathbf{L}} / \mathbf{\%}$ & Plastic limit $\boldsymbol{I}_{\mathrm{P}} / \mathbf{\%}$ & Free expansion rate/\% \\
\hline 1.72 & 2.74 & 37.09 & 19.97 & 60 \\
\hline
\end{tabular}

Table 1. Basic physical parameters of red clay

\section{Measuring index}

Triaxial compression test. The maximum shear stress, shear strength index, elastic modulus and shear modulus of remolded red clay under different water content were got by merged undrained triaxial compression test. Therefore, the effect of freeze-thaw cycles on the mechanical properties of remolded red clay can be analyzed by triaxial tests.

Consolidation compression test. The settlement displacement under different water content and pressure conditions was got through consolidation compression test, and the compression modulus of soil was got through relevant calculation. Therefore, the effect of freeze-thaw cycle on the compression performance of remolded red clay can be analyzed by consolidation compression test.

\section{Analysis of mechanical properties of red clay}

Stress-strain cures. Solidified undrained triaxial compression tests were performed on triaxial specimens of remodeled red clay with different number of freeze-thaw cycles $(0,12)$. The stress-strain curves of the remodeled red clay soil at different water contents are shown in Figure 1. Both after 0 freeze-thaw cycles and after stabilization of freeze-thaw cycles (12 cycles), the soil samples at different water contents showed obvious strain hardening phenomenon. The reason for this phenomenon is that the soil undergoes very obvious brittle damage after shear reaches the maximum shear stress.

From Fig. 1, it can be seen that the maximum shear stress will accumulate with the increase of the 
surrounding pressure when the water content is the same; when the surrounding pressure is certain, the maximum shear stress is gradually decreasing with the increase of the water content. Analysis that the enclosing pressure plays a very important role in the shear process, although the height of the specimen is reduced in the vertical direction, but its lateral will also produce a certain deformation, the particles in the vertical direction will be concentrated extrusion to the lateral region, and the enclosing pressure restricts the lateral deformation of the soil, but also bound the lateral movement of soil particles, so the larger the enclosing pressure, the stronger the restriction, the maximum shear stress will also increase with the strain and increases. As the shear deformation of soil is formed by the interaction movement between soil particles, with the increase in water content, the pour water inside the soil gradually increases, the interaction between soil particles weakens, and the maximum shear stress gradually decreases. 0 freeze-thaw cycles of the maximum shear stress are greater than 12 times after shear stabilization. With the increase in water content, the difference between them gradually decreases under the same surrounding pressure.

The indexes of shear strength after 0 and 12 freeze-thaw cycles: internal friction angle and cohesion were derived from the quasi-side of the molculon, as shown in Table 2. It can be seen from the table that with the increase of water content, the cohesion and internal friction angle of the remodeled red clay are decreasing, and the analysis suggests that with the increase of water content, the weakly bound water inside the soil gradually increases and free water gradually arises, and the contribution of structural suction to the cohesion is weakened, so that the cohesion gradually decreases. The decreasing trend of cohesion gradually increases from $4.48 \%$ to $35.88 \%$ at 0 freeze-thaw cycles. The decreasing trend of cohesive force is gradually decreasing from $65.38 \%$ to $5.93 \%$. the decreasing trend of internal friction angle is the same for 0 freeze-thaw cycles and 12 freeze-thaw cycles, and it gradually increases with the increase of moisture content.
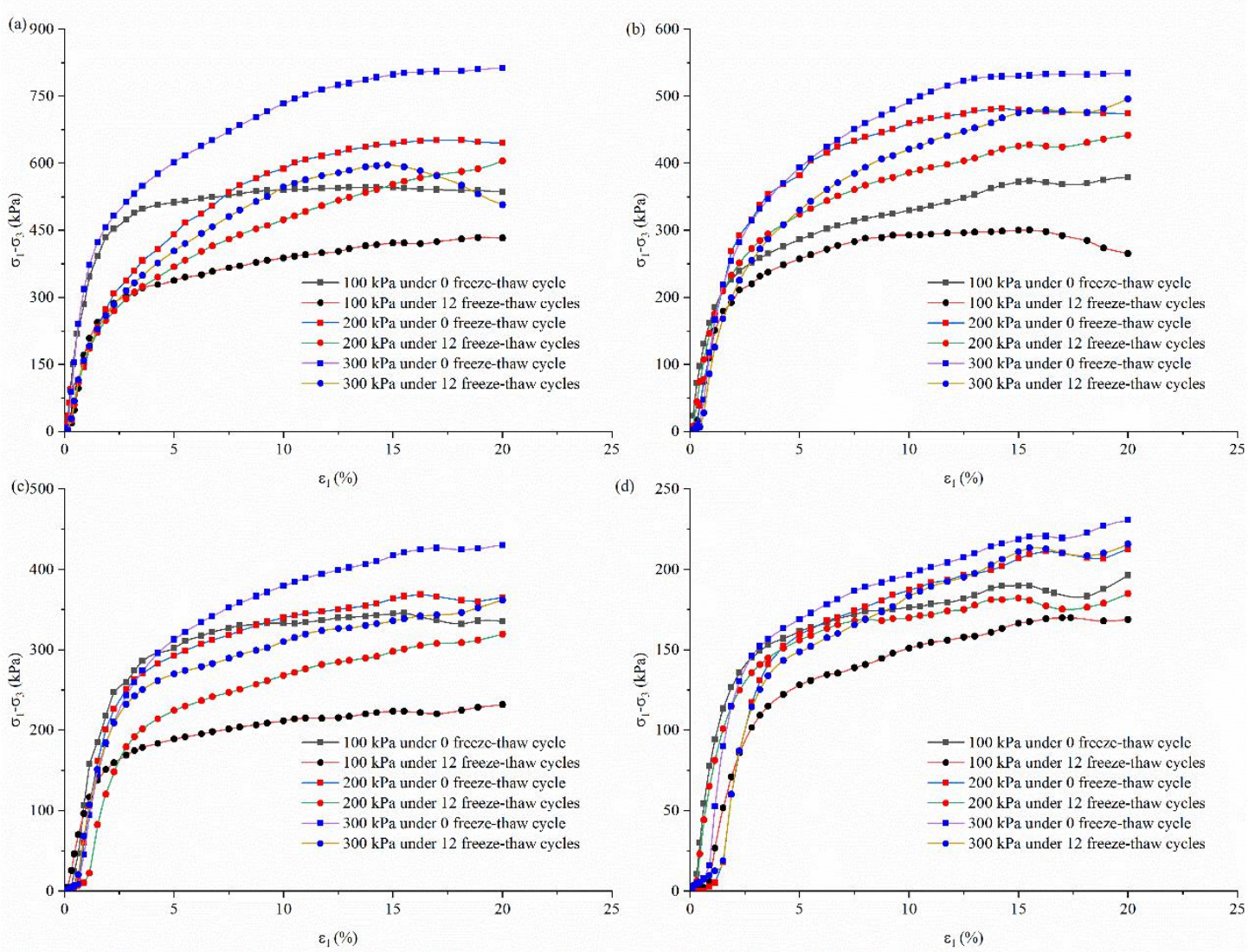

Figure 1.Stress-strain curves (a) Moisture content $15 \%$.(b) Moisture content $18 \%$.(c) Moisture content 
$21 \%$.(d) Moisture content $24 \%$.

\begin{tabular}{|c|c|c|c|c|}
\hline \multirow{2}{*}{$\begin{array}{c}\text { Moisture } \\
\text { content/\% }\end{array}$} & \multicolumn{2}{|c|}{ 0 freeze-thaw cycle } & \multicolumn{2}{c|}{ 12 freeze-thaw cycles } \\
\cline { 2 - 5 } & Cohesion/(kPa) & $\begin{array}{c}\text { Internal friction } \\
\text { angle/( })\end{array}$ & Cohesion/(kPa) & $\begin{array}{c}\text { Internal friction } \\
\left.\text { angle/( } \mathbf{(}^{\circ}\right)\end{array}$ \\
\hline $\mathbf{1 5}$ & 137.91 & 22.65 & 137.61 & 16.31 \\
\hline $\mathbf{1 8}$ & 132 & 16.6 & 83.21 & 17.43 \\
\hline $\mathbf{2 1}$ & 112.13 & 8.59 & 70.75 & 12.54 \\
\hline $\mathbf{2 4}$ & 82.52 & 3.84 & 66.79 & 5.33 \\
\hline
\end{tabular}

Table 2. Shear strength index of remolded red clay under different moisture content.

Elastic modulus. Elastic modulus is defined as the material in the elastic deformation stage where the stress and strain become proportional to each other, i.e., it satisfies Hooke's law. In the solidification undrained triaxial test, the remodeled red clay undergoes elastic deformation when the strain is tiny, so it can take the ratio of stress to strain as the elastic modulus of the remodeled red clay at that stage. From Fig. 1 , it can be seen that when the number of freezing and thawing is certain, in the elastic stage, the curves are approximately parallel and the elastic modulus is approximately equal under different surrounding pressures at the same water content, so the average value of the elastic modulus under three surrounding pressures is taken at the same water content, and the calculation results are shown in Fig. 2.

Whether it is not freeze-thaw cycle or freeze-thaw cycle after 12 times of stability, the elastic modulus decreases with the increase of moisture content. The elastic modulus without freeze-thaw cycles were 40.30,23.76,17.34 and 7.42 $\mathrm{MPa}$, respectively. The maximum difference of elastic modulus was that the moisture content decreased by $69.61 \%$ from $15 \%$ to $18 \%$. After 12 freeze-thaw cycles, the elastic modulus showed a linear decrease. Under the same moisture content, the elastic modulus of 0 freeze-thaw cycles was greater than that of 12 freeze-thaw cycles after stabilization, but the degree of decrease was gradually reduced, and the decrease was reduced from $82.06 \%$ to $14.33 \%$.

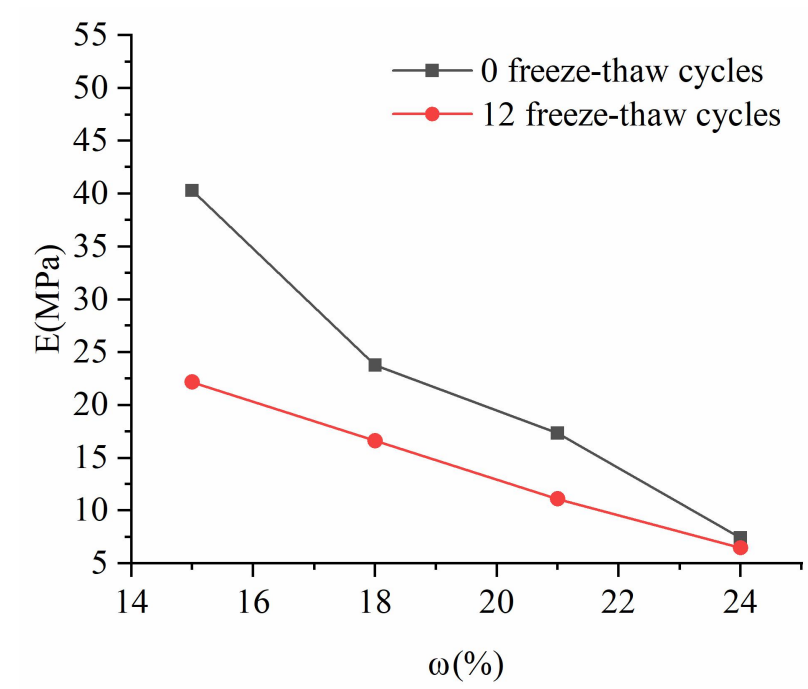

Figure 2. Elastic modulus of red clay with different moisture content

Poisson ratio. In the consolidation compression test, $\sigma_{\mathrm{z}}$ is the vertical pressure. Due to the lateral complete lateral limit, so :

$$
\begin{gathered}
\varepsilon_{\mathrm{x}}=\varepsilon_{\mathrm{y}}=0 \\
\sigma_{\mathrm{x}}=\sigma_{\mathrm{y}}
\end{gathered}
$$

Where: $\varepsilon_{\mathrm{x}}$ is the strain in x-direction; $\varepsilon_{\mathrm{y}}$ is the strain in y-direction; $\sigma_{\mathrm{x}}$ is the stress in x-direction; $\sigma_{\mathrm{y}}$ is 
the stress in $\mathrm{y}$-direction.

Using the generalized Hooke ' s law under three-dimensional stress state, according to formula ( 1 ):

$$
\varepsilon_{\mathrm{x}}=\frac{\sigma_{\mathrm{x}}}{E_{0}}-\mu\left(\frac{\sigma_{\mathrm{y}}}{E_{0}}+\frac{\sigma_{\mathrm{z}}}{E_{0}}\right)=0
$$

Where: $E_{0}$ is the elastic modulus; $\mu$ is the poisson ratio.

Replace formula ( 2 ) with formula ( 3 ) by:

$$
\sigma_{\mathrm{x}}=\frac{\mu}{1-\mu} \sigma_{\mathrm{z}}
$$

Consider $\varepsilon_{\mathrm{z}}$ :

$$
\varepsilon_{\mathrm{z}}=\frac{\sigma_{\mathrm{Z}}}{E_{0}}-\mu\left(\frac{\sigma_{\mathrm{X}}}{E_{0}}+\frac{\sigma_{\mathrm{y}}}{E_{0}}\right)=\frac{\sigma_{\mathrm{z}}}{E_{0}}\left(1-\frac{2 \mu^{2}}{1-\mu}\right)
$$

By substituting the lateral compression condition $\varepsilon_{\mathrm{z}}=\frac{\sigma_{\mathrm{z}}}{E_{\mathrm{s}}}$, then :

$$
\begin{aligned}
& \frac{\sigma_{\mathrm{z}}}{E_{\mathrm{S}}}=\frac{\sigma_{\mathrm{z}}}{E_{0}}\left(1-\frac{2 \mu^{2}}{1-\mu}\right) \\
& E_{0}=E_{\mathrm{S}}\left(1-\frac{2 \mu^{2}}{1-\mu}\right)
\end{aligned}
$$

Therefore, Poisson ratio of soil can be determined by elastic modulus and compression modulus. It can be seen from the known literature that the compression state corresponding to the pressure interval of 100 $\mathrm{kPa}$ to $200 \mathrm{kPa}$ is generally used to evaluate the compressibility of soil, the ratio of the vertical stress increment $\Delta p$ (from $p_{1}$ to $p_{2}$ ) and the corresponding strain increment $\Delta \varepsilon$ under the condition of complete lateral confinement, also known as the compression modulus, as shown in Formula (8):

$$
E_{\mathrm{S}}=\frac{\Delta p}{\Delta \varepsilon}=\frac{\Delta p}{\Delta H / H_{1}}
$$

where: $H_{1}$ indicates the height of the soil from a pressure at $100 \mathrm{kPa}$.

Through the consolidation compression test, the corresponding compression amount under each pressure is obtained, and the compression curve is plotted, as shown in Fig. 3 and Fig. 4. The compression modulus of each state is calculated by formula (8), and the corresponding Poisson ratio is calculated according to formula (7), such as table 3. After 0 freeze-thaw cycles, the final heights corresponding to $15 \%$, $18 \%, 21 \%$ and $24 \%$ moisture contents were $19.84 \mathrm{~mm}, 19.645 \mathrm{~mm}, 19.572 \mathrm{~mm}$ and $19.172 \mathrm{~mm}$, respectively. The final heights after 12 freeze-thaw cycles were $19.62 \mathrm{~mm}, 19.596 \mathrm{~mm}, 19.263 \mathrm{~mm}$ and $18.881 \mathrm{~mm}$. It can be seen from the figure that the settlement rate increases with the increase of water content, and increases with the increase of overlying load. The settlement of 0 freeze-thaw cycles is less than that of 12 freeze-thaw cycles. With the increase of overlying load, the settlement trend is almost linearly decreased. The analysis shows that with the increase of water content and pressure, the pore water inside the soil increases and the pore becomes larger. After the influence of pressure, the pore water discharges, and the effect on the internal pores of the soil, is more significant. The degree of compaction of the soil increases, and the final settlement increases. Because of the repeated freeze-thaw effect, the internal structure of soil changes, and it is more vulnerable to pressure, so the effect of settlement is more obvious. 


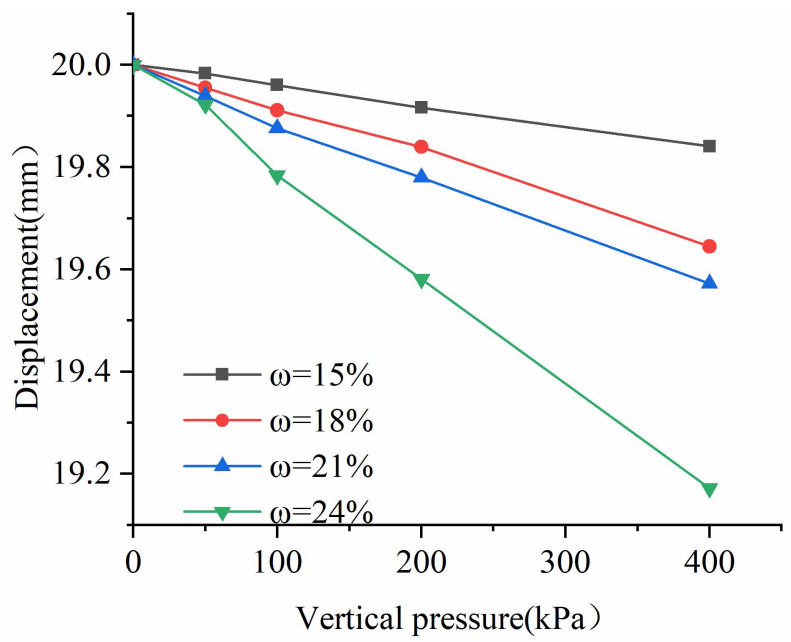

Figure 3. Consolidation displacement during 0 freeze-thaw cycles

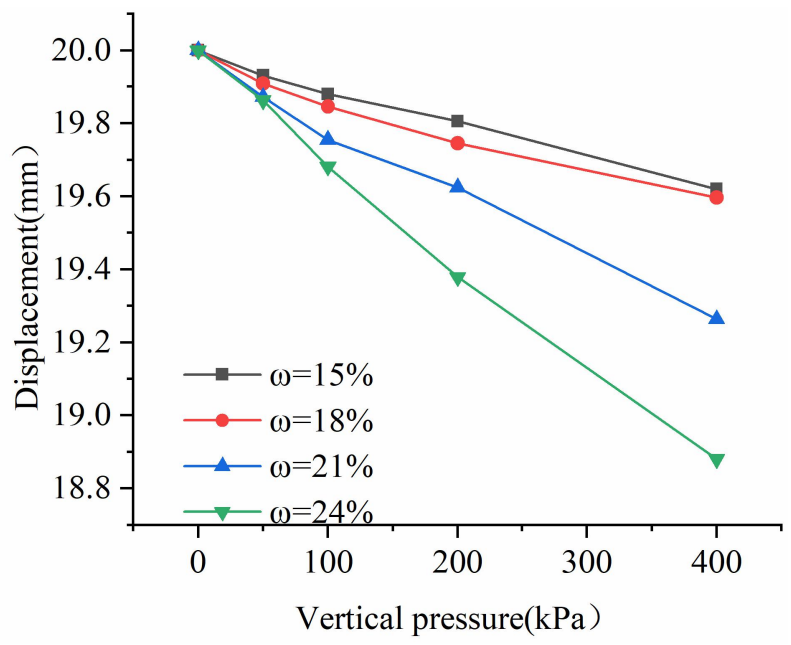

Figure 4. Consolidation displacement during 12 freeze-thaw cycles

\begin{tabular}{|c|c|c|c|c|}
\hline Moisture content (\%) & Cycle number(times) & $E_{0}(\mathrm{MPa})$ & $E_{\mathrm{s}}(\mathrm{MPa})$ & $\mu$ \\
\hline \multirow{2}{*}{15} & 0 & 40.30 & 45.36 & 0.21 \\
\cline { 2 - 5 } & 12 & 22.18 & 26.51 & 0.24 \\
\hline \multirow{2}{*}{18} & 0 & 23.76 & 27.65 & 0.23 \\
\cline { 2 - 5 } & 12 & 16.60 & 19.85 & 0.25 \\
\hline \multirow{2}{*}{21} & 0 & 17.34 & 20.49 & 0.24 \\
\hline \multirow{2}{*}{24} & 12 & 11.11 & 15.10 & 0.30 \\
\cline { 2 - 5 } & 0 & 7.42 & 9.79 & 0.29 \\
\hline & 12 & 6.49 & 8.85 & 0.31 \\
\hline
\end{tabular}

Table 3. Values of elastic modulus, compressive modulus and Poisson ratio of red clay

It can be seen from the table that with the increase in water content, the elastic modulus and compression modulus decrease without and after 12 freeze-thaw cycles. Without freeze-thaw cycles, the maximum difference of elastic modulus is $16.54 \mathrm{MPa}$, and the minimum difference is $6.42 \mathrm{MPa}$. The maximum difference of compression modulus is $17.71 \mathrm{MPa}$, and the minimum difference is $7.16 \mathrm{MPa}$. The maximum difference of elastic modulus was $5.5 \mathrm{MPa}$ and the minimum difference was $4.62 \mathrm{MPa}$ in 12 freeze-thaw cycles. The maximum difference of compression modulus is $6.66 \mathrm{MPa}$, and the minimum 
difference is 4.75 MPa. At the same moisture content, the elastic modulus and compression modulus without freeze-thaw cycles are greater than 12 freeze-thaw cycles. The Poisson ratio increases with the increase in moisture content, and the Poisson ratio is less than 12 freeze-thaw cycles without freeze-thaw cycles. In the moisture content range of $15 \%-24 \%$, the Poisson ratio of 0 freeze-thaw cycles is $0.21-0.29$, and the Poisson ratio of 12 freeze-thaw cycles is $0.24-0.31$.

Shear modulus. Known elastic modulus and Poisson ratio can calculate the shear modulus. For formula (9):

$$
G=\frac{E_{0}}{2(1+\mu)}
$$

where: $G$ indicates the shear modulus.

The shear modulus of 0 freeze-thaw cycles were 16. 65,9. 66,6. 99 and 2. $88 \mathrm{MPa}$, respectively. The shear modulus after 12 freeze-thaw cycles were 8.94, 6.64, 4.27 and $2.48 \mathrm{MPa}$, respectively. Combined with the Fig. 5 , it can be seen that the shear modulus of 0 freeze-thaw cycles is greater than that of 12 freeze-thaw cycles at the same moisture content. The larger the shear modulus is, the more difficult the shear deformation of the soil is to occur, showing that the increase in the number of freeze-thaw cycles makes the soil more prone to shear deformation. When the moisture content is $15 \%, 0$ times is 1.86 times of 12 times, and when the moisture content is $24 \%, 0$ times is only 1.16 times of 12 times. It shows that, with the increase in moisture content, the influence of freeze-thaw cycles on shear modulus is getting smaller and smaller. With the increase in water content, the shear modulus decreases linearly, showing that the increase in water content makes the shear deformation of soil increase, and the more prone to shear failure.

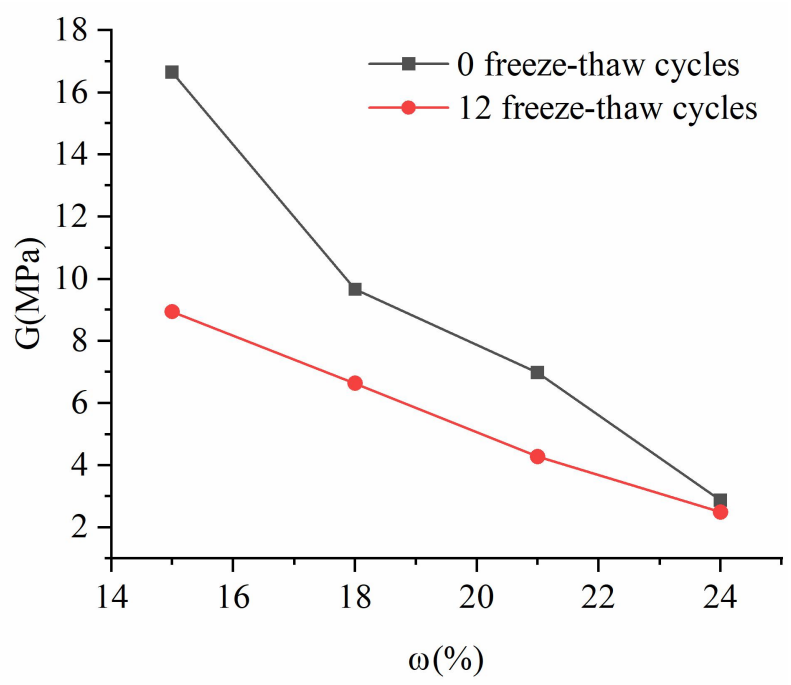

Figure 5. Shear modulus of red clay

\section{Conclusion}

In this study, the freeze-thaw cycle test of remolded red clay in Changzhi area of Shanxi Province was carried out. Through mechanical test and theoretical derivation, the mechanical parameters of remolded red clay under different moisture content are got, and some rules are found out. The results can be summarized :

1. Under the action of freeze-thaw cycles, the soil shows the trend of strain hardening, and the maximum shear stress increases with the increase of the surrounding pressure when the water content is certain; when the surrounding pressure is certain, the maximum shear stress gradually decreases with the increase of the water content.

2. The shear strength indexes of the soils change in the same trend under 0 and 12 freeze-thaw cycles, and 
the cohesion and internal friction angle decrease gradually with the increase of water content. The decreasing trend of the internal friction angle remained the same, and accumulated with the increase in water content.

3. The elastic modulus, compressive modulus, Poisson's ratio and shear modulus of the soil were derived using triaxial and consolidation tests and combined with theoretical derivation. With the increase in water content, the elastic modulus, compressive modulus and shear modulus decreased and Poisson's ratio increased, and the mechanical parameters at 0 freeze-thaw cycles were greater than those at 12 freeze-thaw cycles. The elastic modulus decreased by $69.61 \%$ at most at 0 freeze-thaw cycles and linearly at 12 freeze-thaw cycles. The Poisson ratio was $0.21 \sim 0.29$ at 0 freeze-thaw cycles and $0.24 \sim 0.31$ at 12 freeze-thaw cycles. The shear modulus at 0 freeze-thaw cycles was $1.86 \sim 1.16$ times higher than that at 12 freeze-thaw cycles, and the increase in water content made the soil more prone to shear deformation.

\section{References}

1. Leuther. F., \& Schlueter. S., Impact of freeze-thaw cycles on soil structure and soil hydraulic properties. SOIL. 7, 179-191 (2021).

2. Jabro. J.D., Iversen. W.M., Evans. R.G., Allen. B.L., \&Stevens. W.B. Repeated Freeze-Thaw Cycle Effects on Soil Compaction in a Clay Loam in Northeastern Montana. Soil Sci. Soc. Am. J. 78, 737-744 (2014).

3. Li. Z. Y., Yang. G. S., \& Liu. H. The Influence of Regional Freeze-Thaw Cycles on Loess Landslides: Analysis of Strength Deterioration of Loess with Changes in Pore Structure. Water-Sui. 12, 3047(2020).

4. Tan, L., \& Kong, L., Fundamental property and microstructure model of red clay.Chin.j.Geotechn.Eng.4,458-462(2021)

5. Chen, Y., Li, B., Xu, Y., Zhao, Y.\& Xu, J. Field study on the soilwater characteristics of shallow layers on red clay slopes and its application in stability analysis.Arab.J.Sci.Eng.44,5107-5116(2019)

6. Zhang, Z. L., Wang, T., Wu, S. R., Tang, H.M.\& Liang, C. Y. Dynamics characteristic of red clay in a deep-seated landslide, Northwest China: An experiment study.Eng.Geol.239,254-268.(2018)

7. Han, G. The features of engineering geology of red clay in Guiyang. Geol Guizhou 3,292-296(1992)

8. Basma,A.A.,Al-Homoud,A.S.,Malkawi,A.I.H.\&Al-Bashabsheh,M.A.Swelling-shrinkage behavior of natural expansive clays. Appl. Clay Sci.11,211-227(1996)

9. Zhang. Y. Z., Pu. S. Y., Li. R. Y. M., \& Zhang. J., Microscopic and mechanical properties of undistributed and remoulded red clay from Guiyang, China. Sci. Rep.-UK. 10,18003(2020).

10. Yuan. J., Liu. Z. H., Hu. G. X., \&Fang. Y.G., Experimental Analysis of the Influence of Soil Composition on Strength Characteristics. Soil Mech. Found. Eng.+. 55, 325-332 (2018).

11. Wang. Q., Li. C.Y., Liu. Y. F., Sun. D. Y., Zhang. X. F.,\& Ma. B., Mechanical Properties of Saline Soil Under the Influence of Different Factors. Fresen. Environ. Bull. 28, 1366-1373 (2019).

12. Lian. B. Q., Peng. J. B., Wang. X. G., \&Huang. Q.B., Moisture content effect on the ring shear characteristics of slip zone loess at high shearing rates. B. Eng. Geol. Environ. 79, 999-1008 (2020).

13. Ahmed. A., Gariepy. Y., \&Raghavan. V., Influence of wood-derived biochar on the compactibility and strength of silt loam soil. Int. Agrophys. 31, 149-155 (2017).

14. Xu. X. T., Li. Q. L., Lai. Y., Pang. W. T., \&Zhang. R.P., Effect of moisture content on mechanical and damage behavior of frozen loess under triaxial condition along with different confining pressures. Cold Reg. Sci. Technol. 157, 110-118 (2019).

15. Tang. L., Cong. S. Y., Geng. L., Ling. X. Z., \&Gan. F., The effect of freeze-thaw cycling on the mechanical properties of expansive soils. Cold Reg. Sci. Technol. 145, 197-207 (2018).

16. Chen. S.F., Kong. L.W., \&Xu. G.F., An effective way to estimate the Poisson's ratio of silty clay in seasonal frozen regions. Cold Reg. Sci. Technol. 154, 74-84 (2018).

17. Shastri. A., Sanchez. M., Gai. X.R., Lee. M. Y., \& Dewers. T., Mechanical behavior of frozen soils: Experimental investigation 
and numerical modeling. Comput. Geotech. 138, 104361(2021).

18. Liu. K., Ye. W. J., \&Jing. H.J., Shear Strength and Microstructure of Intact Loess Subjected to Freeze-Thaw Cycling. Adv. Mater. Sci. Eng. 2021, 1173603(2021).

19. Zhou. Z. W., Ma. W., Zhang. S. J., Mu. Y. H.,\& Li. G.Y., Effect of freeze-thaw cycles in mechanical behaviors of frozen loess. Cold Reg. Sci. Technol. 146, 9-18 (2018).

20. Wang. M., Meng. S. J., Sun. Y. Q., \&Fu. H.Q., Shear strength of frozen clay under freezing-thawing cycles using triaxial tests Earthq. Eng. Eng. Vib. 17, 761-769 (2018)

21. Tian.L. H., Yu. L. L., Liu. S. M.,\& Zhang. B., Deformation Research of Silty Clay under Freeze-Thaw Cycles. KSCE J. Civ. Eng. 24, 435-442 (2020)

22. Cheng. S. K., Wang. Q., Wang. J. Q., \& Han. Y., Experimental Study on Undrained Shear Properties of Saline Soil under Freeze-Thaw Cycles. Geofluids. 2021, 9987414(2021).

23. Wang. T., Zhang. H., Zhou. G. Q., \& Liu .X.Y., Evaluation of variability characteristics of mechanical parameters of artificially frozen clay in deep alluvium. Cold Reg. Sci. Technol. 171, 102978(2020).

24. Masin. D., \& Rott. J., Small strain stiffness anisotropy of natural sedimentary clays: review and a model. Acta Geotech. 9 299-312 (2014)

25. Suwal. L. P., \& Kuwano. R., Statically and Dynamically Measured Poisson's Ratio of Granular Soils on Triaxial Laboratory Specimens. Geotech. Test. J. 36, 493-505 (2013).

26. Wang. T. L., Liu. Y. J., Yan. H., \&Xu. L., An experimental study on the mechanical properties of silty soils under repeated freeze-thaw cycles. Cold Reg. Sci. Technol. 112, 51-65 (2015).

27. Ozgan. E., Serin. S., Erturk. S.,\& Vural. I., Effects of Freezing and Thawing on the Consolidation Settlement of Soils. Soil Mech Found. Eng.+. 52, 247-253 (2015).

28. Wang. H. X., Wu. Z. Z., Tan. Y. Z., Cui. X.Z., Zuo. Q.J., Wang. L.H. \&Lu. L.Q., Characteristics of pore structure of stabilized/solidified sediments during freeze-thaw cycles. Constr. Build. Mater. 259, 119804(2020).

29. Xu. Y., Wu. Y. J., Zhang. X.D.,\& Chen. G., Effects of freeze-thaw and chemical preconditioning on the consolidation properties and microstructure of landfill sludge. Water Res. 200, 117249(2021).

\section{Acknowledgements}

We gratefully acknowledge the public service sector special funds from the Provincial Natural Science Foundation of Anhui (Grant No.2008085ME143) and the Graduate Innovation Foundation of Anhui University of Science and Technology(2020CX2027).

\section{Author contributions}

B.L.: Conceptualization, Data curation, Formal analysis, Investigation, Methodology, Project administration, Software, Visualization, Writing - original draft, Writing - review \& editing. Z.T.: Conceptualization, Data curation, Formal analysis, Investigation, Methodology, Project administration, Software, Visualization, Writing - original draft, Writing - review \& editing. L. J.\&Y.Z: Assistance with experiments. 